\title{
COMPARISON OF DISPATCHING RULES IN JOB-SHOP SCHEDULING PROBLEM USING SIMULATION: A CASE STUDY
}

\author{
Kaban, A. K. ; Othman, Z. \& Rohmah, D. S. ${ }^{* *}$ \\ *School of Information Technology, Faculty of Information Science and Technology, \\ National University of Malaysia, 43600 Bangi, Selangor Darul Ehsan, Malaysia \\ ${ }^{* *}$ Department of Industrial Engineering, Langlangbuana University, \\ 40261 Bandung, Karapitan Street 116, Indonesia \\ E-Mail: aricko.khena@msn.com, zalinda@ftsm.ukm.my,de2_siti_rohmah@yahoo.com
}

\begin{abstract}
Industries nowadays must be able to quickly adapt with the customer and improve product quality to survive in the competitive edge. Job shop scheduling is crucial in the manufacturing world and exists within most manufacturing sectors. In the manufacturing world, scheduling problems are extensively implementing the dispatching rules. The procedures are designed to provide good solutions to complex problems in real-time. This paper describes the importance of dispatching rules in improving the performance of the factory. This study evaluates total of44dispatching rules with the classification of hybrid and single rules. The performance of each rule compared and summarized to determine the final ranking for all the different dispatching rules. The result shown that MTWR (Most Total Work Remaining) rule performs well in almost all measurements as well as hybrid dispatching rules is not generating the best rules compared to single dispatching rule. A set of data from an automotive industry use to simulate the job-shop production floor.

(Received in August 2011, accepted in March 2012. This paper was with the authors 2 months for 2 revisions.)
\end{abstract}

Key Words: Job Shop, Dispatching Rules, Simulation, ARENA

\section{INTRODUCTION}

Nowadays, industries have to face the intensified global competition and advance in the field of information and technology. Manufacturing cycle, quality and service are the major concerns in the manufacturing industries for them to survive in the marketplace. They must be able to quickly adapt to their customers and improve product quality. Fast responding to rapid changes in technology, demanfluctuations, and design changes are also important. These factors require companies to emphasize on automated systems to improve productivity and quality, while reducing cost simultaneously. Companies that are not being able to revise their strategies and, accordingly, modify their organizational processes, will face a risk to eliminate from the competitive edge [1].

Variations of production control techniques applied in order to increase the total production, reduce the total time completion, and deliver the product on time. One method to increase the production of an industry is to create proper scheduling for the components on the available machines so that the order will complete on time, maximizing the use of the resources and minimizing the average waiting time [2]. Scheduling exists in most manufacturing and production systems, as well as in most information-processing environments. In production management, scheduling plays a vital role that is important to ensure the production system runs orderly and explores its potential capacity [3].

Job shop scheduling is extremely difficult to make both in practice and in theory. It is based on the fact that so many parameters to be considered. There are several approaches to 
scheduling problems, such as analytical techniques, meta-heuristic algorithms, rule-based approach and simulation approach. Traditional analytical techniques and simple mathematical models are currently inadequate to analyse the complex manufacturing environments. In addition, analytical models often use mathematical programming techniques and it is not practical for solving a complex scheduling problem. Simulation is one of the powerful tools for testing the efficiencies of different scheduling policies [4]. It can simulate a long period in real life within a reasonably short computer running time of several seconds or minutes. This saves many long-time observation costs. Moreover, simulation can help to get the result of future time without any real change to machine layout or the amount of machines [5].

\section{DISPATCHING RULES}

Scheduling provides a basis for assigning jobs to a work centre. Sequencing (also referred to as dispatching) specifies the order in which jobs should be complete at each centre. The sequencing methods referred to as priority rules for sequencing or dispatching jobs to a work centre. In the manufacturing world, scheduling problems are extensively implementing the dispatching rules. The procedures designed to provide good solutions to complex problems in a real-time production environment [6]. Most of the previous researchers, until this current time, are using dispatching rules to optimize the job-shop scheduling problem [6], [7], [9], and [11]. Impacts generated by the dispatching procedure in the queuing networks are very difficult to be explained using analytical techniques [8]. However, the study of the dynamic job shop scheduling has made rapid progress by using computer simulation. In these approaches, several dispatching rules or other scheduling policies are compared using simulation [9].

Reference [10] classified over 100 scheduling rules and attempted to explain the general idea behind different rules. These rules classified into static and dynamic rules. Static rules are the ones in which the job priority values do not change as a function of the passage of time, i.e. it is not time dependent. They are just a function of a job and/or machine data. Dynamic rules are time dependent. Reference [6] used dispatching rules in semiconductor manufacturing and it showed that dispatching heuristics provides schedules quickly, that are easy to understand, easy to apply, and require relatively small computation time. The primary disadvantage of dispatching rules is that these cannot hope for optimal solutions for all performance measures in the dynamic job shop [11]. It is because the dispatching decision made only according to local information.

References [11-12] designed dispatching rules to improve the tardiness performance. They proposed a new dispatching rule (i.e. RTSLACK), which is based on maximizing the slack time of the remaining tasks in the manufacturing resources queues in a series of single machine and hybrid flow shop scheduling problem instances. Reference [12] designed an effective composite dispatching rule that minimizes total tardiness through a Genetic Programming approach in a flexible job-shop model. Their research implied that the way to combine the rules could significantly affect the optimality of the schedules.

Dispatching rules are better than genetic algorithms in three respects [13]. They found that dispatching rules are able to create various solutions to solve many problems observed, whereas genetic algorithms only provide one solution to minimize makespan. In addition, solutions obtained by genetic algorithms yielded scattering results, whereas the solutions obtained by dispatching rules yielded steady results. Thirdly, genetic algorithms require the use of a computer because of the large number of parameters to specify, whereas dispatching rules can obtain simple solutions in an urgent production situation.

Reference [11] combining several single dispatching rules to provide efficient dispatching rules for dynamic job shop scheduling and they found that no single rule is effective in 
minimizing all measures of performance. Reference [14] investigated the advantages of using a combination of dispatching rules for cost performance and they found that the combination rules performs well in reducing both mean and variability of waiting cost. Reference [15] proposed a dispatching rule for non-identical parallel machines that considered product quality, it enabled job shops to keep due dates, while satisfying quality restrictions. The use of a quality threshold in dispatching can facilitate manufacturing products with a desired quality level [16-17].

From the literature reviewed, Dispatching heuristic was able to provide not only a good solution but also the best solutions for the system observed. Dispatching rules have a significant role within the dynamic context because of their ease of implementation and compatibility with the dynamic nature of manufacturing systems.

\section{PROBLEM STATEMENT}

Job shops are an important part in the world of manufacturing. Peoples are not able to maintain their living standards normally without it [18]. The definition of job shop is "a group of manufacturing operations where the productive resources are organised according to function and the work passes through in varying lots and routings" [19].

This paper can state the problem addressed as follows: Given a large job shop and a number of jobs that consist of local disturbances, we determine how to schedule the jobs, so that the performance observed is maximum. The job shop problem described as [20-21]: there are $m$ machines with $n$ operations and $j$ jobs. Therefore, there will be $m^{n}$ possible for the allocation rules, $(n !)$ possible sequences, $\left(m^{n} \cdot n !\right)$ possible processes, $\left((j !)^{m}\right)$ schedules available for each job, and $\left(m^{n} \cdot n !\right)^{j}$ schedules available for each combination of processes. These give $\left(\left(m^{n} \cdot n !\right)^{j} \cdot(j !)^{m}\right)$ schedules evaluated for each job-shop scheduling problem. Let say if $m=n=j=2$, there will be 256 possible numbers of schedules, but if $m=n=j$ increase to the number of 3 , there will be 91833048 possible number of schedules and these numbers will rapidly increase in proportion to increment of resources.

\subsection{Design of experiment}

This paper describes a simulation study for automotive supply industry with job shop environment. This company produces components for vehicle and several industrial components. In observed company, 10 operations/products produced on 14 machines. Routing and processing time are dependent on the group of items. Routing length can vary from three to seven operations and there is no flexibility on the routing. The following assumptions made while built the simulation model [12], [22]:

- All the items are ready at the start of the simulation.

- No due dates specified.

- Each machine can perform only one operation at a time.

- Each machine has an operator.

- Transportation time between two consecutive work centres is deterministic and assumed to be 15 time units for all shop types.

- Machines have breakdowns every 3 months, and it take a whole day to repair.

- Set-up times assumed to be negligible.

- All the parts have to leave the system when all their operations are finished.

ARENA simulation software is used to develop the simulation model for the job-shop scheduling problems. ARENA has many advantages in simulation and modelling of discrete system. The simulation model executed for one simulation year based on 8 hours/day and 5 
days/week. Therefore, the total run for a year is 250 days (include public holiday) with $n=5$ replications.

\subsection{Performance measurement}

In this study, simulation experiments collect several measurements of shop performances. The objective is to evaluate the performance of different dispatching rules based on these performance measures in real job shop scheduling environment. Several performance measures used to evaluate which alternative that performs well in observed system. The performance measures collected are:

- WIP average

It is the average number of jobs in the system. The relationship between the number of jobs in the system and the WIP inventory will be high. Therefore, the fewer numbers of jobs are in the system, the lower the inventory.

- The total average time that required to complete an operation

One of the common objectives in job shop scheduling is to minimize the makespan. The makespan optimization generally ensures high utilization of the production resources, early satisfaction of the customers' demands and the reduction of in-process inventory by minimizing the total production run.

- Total waiting time average for each part

Waiting time is the time that the entity (parts) spends waiting in the system for available machine and operator.

- Queue waiting average time

Queue time is the time that part $i$ spent waiting in the machine $j$ queue.

- Queue length average for each work centre

Queue length is the number of parts that are waiting in the machine queue.

\section{SIMULATION EXPERIMENT}

The base simulation model was used FIFO as initial dispatching rule. In this project, beside LIFO rule, static and dynamic dispatching rules are also use to enhance the plant performance. Static rule are the ones in which the job priority values does not change as a function of the passage of time, it is not time dependent. There are 3 parameters that assigned to be static:

- Processing Time: Time required to operate part $i$ on machine $j$.

- Process Sequence: Total sequence required for part $i$ to complete the operation.

- Total Processing Time: Total time required for part $i$ to complete the operation.

Dynamic rules are time dependent. It is the ones in which the job priority values change as a function of the passage of time. There are also 3 parameters that assigned to be dynamic in this project:

- Creation Time: The time when part $i$ was created.

- Waiting Time: The time that part $i$ spent when waiting in the queue line on machine $j$.

- Total Work Remaining: Total work remaining for part $i$ to complete the operation.

Based on parameters described, 14 dispatching rules adopted in this project as shown in Table I.

Up to the current knowledge, there is no single dispatching rule that minimizes most of the performance measures [11], particularly in the dynamic environment of job shop scheduling. Therefore, a new dispatching rule is carry out in this study by using a multiplicative combination of rules that minimize most of the performance measures. Each of 
parameter in a single rule multiplied to obtain a new hybrid dispatching rules. For example SPT and SPS:

where,

$$
Z=P T_{i j} \times P S_{i}
$$

i - Set of operation

$j \quad$ - Set of Machine

$P T$ - Time required to operates operation $i$ on machine $j$

$P S$ - Total sequence require for operation $i$ to complete the operation

Table I: Selected dispatching rules.

\begin{tabular}{|l|c|l|l|}
\hline No. & Rules & \multicolumn{1}{|c|}{ Description } & Type \\
\hline 1 & FIFO & First In First Out & Static \\
\hline 2 & LIFO & Last In First Out & Static \\
\hline 3 & SPT & Shortest Processing Time & Static \\
\hline 4 & LPT & Longest Processing Time & Static \\
\hline 5 & SPS & Shortest Process Sequence & Static \\
\hline 6 & LPS & Longest Process Sequence & Static \\
\hline 7 & STPT & Shortest Total Processing Time & Static \\
\hline 8 & LTPT & Longest Total Processing Time & Static \\
\hline 9 & ECT & Earliest Creation Time & Dynamic \\
\hline 10 & LCT & Longest Creation Time & Dynamic \\
\hline 11 & SWT & Shortest Waiting Time & Dynamic \\
\hline 12 & LWT & Longest Waiting Time & Dynamic \\
\hline 13 & LTWR & Least Total Work Remaining & Dynamic \\
\hline 14 & MTWR & Most Total Work Remaining & Dynamic \\
\hline
\end{tabular}

The rule that give the lowest $Z$ value has the highest priority to be processed. Table II shows the experiment for this stage. It is the combination between each parameters used in this paper. Fifteen (15) combined parameters generated, each of these parameters are set to high attribute and low attribute value. Therefore, this study will evaluate the 30 hybrid dispatching rules.

Table II: Combined dispatching rules.

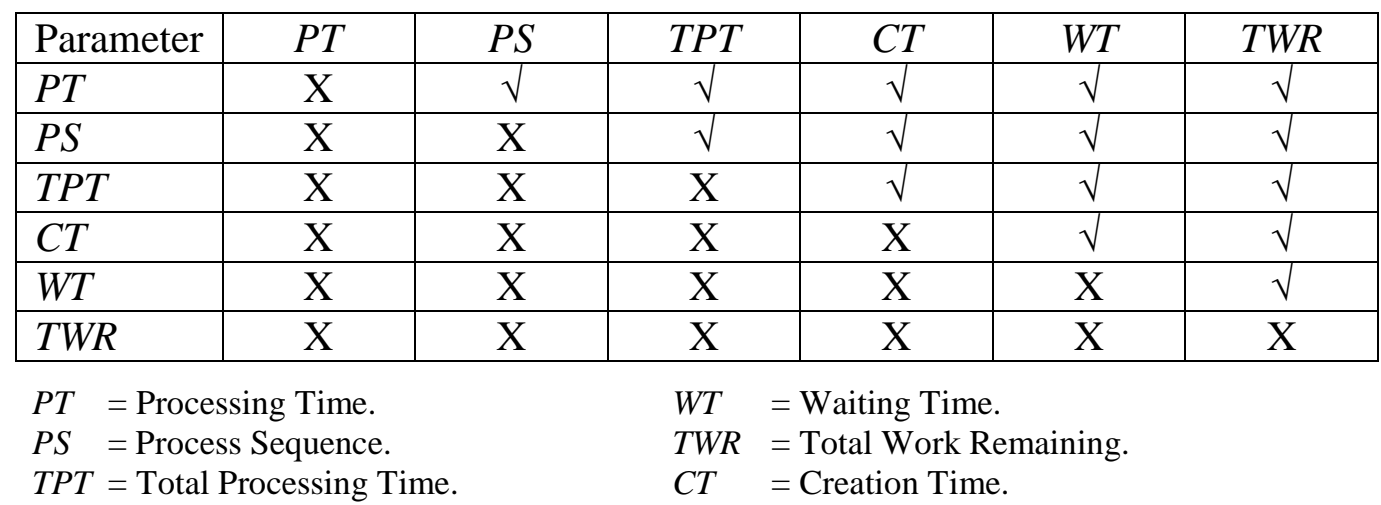

\section{RESULTS AND DISCUSSION}

The results of simulation models are analysed and discussed in this section. In this simulation, a confidence interval of 0.95 has been set to provide insight to the output variability. For 
appropriate statistic, ARENA simulation software includes a category called "half width" in the reports. The half width is half the range of the confidence interval. This category is included to help determine the reliability of the results, and determine when to terminate a replication/run once a specified level of accuracy reached. This value may be interpreted "in $95 \%$ of trials, the sample mean would be reported as within the interval sample mean \pm half width” [23].

\subsection{Single dispatching rules}

Fig. 1 shows the relationship between WIP and different single dispatching rules. It can be seen that LWT rule shown the best performance for this measurement, while LPT shown the worst performance for this criteria.

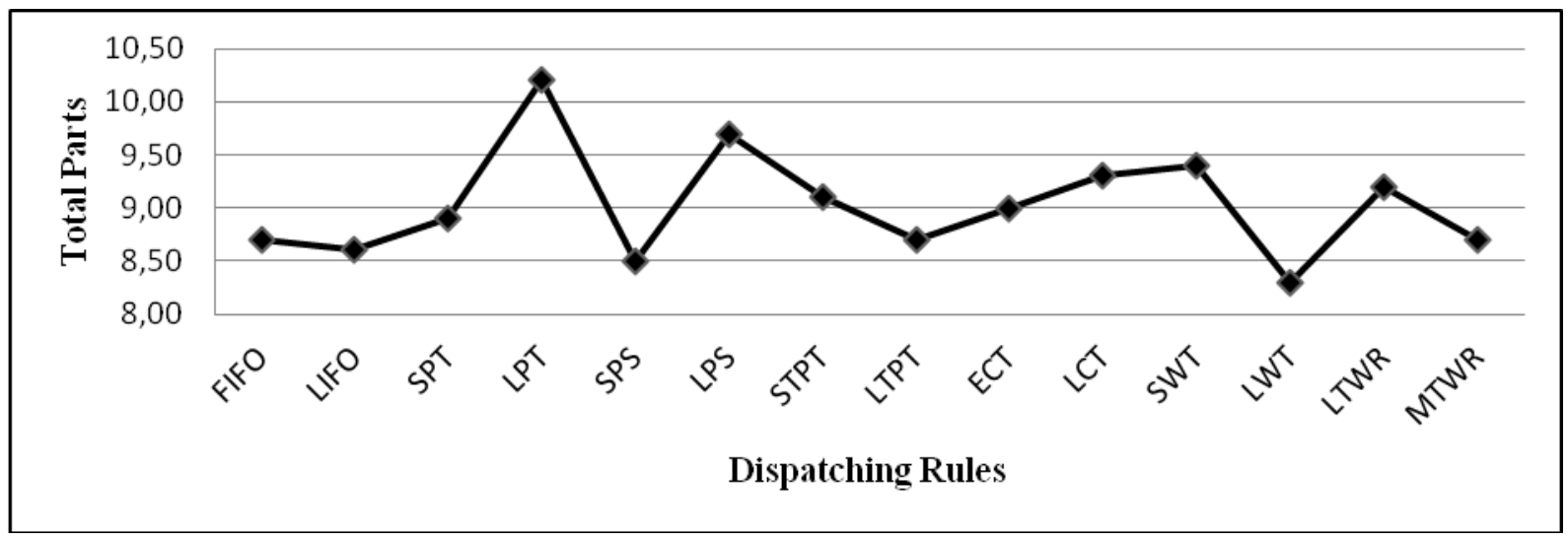

Figure 1: Performance of each single dispatching rule on WIP.

Similarly, Figs. 2 and 3 show the performance of each single dispatching rule on other selected performance measurement.

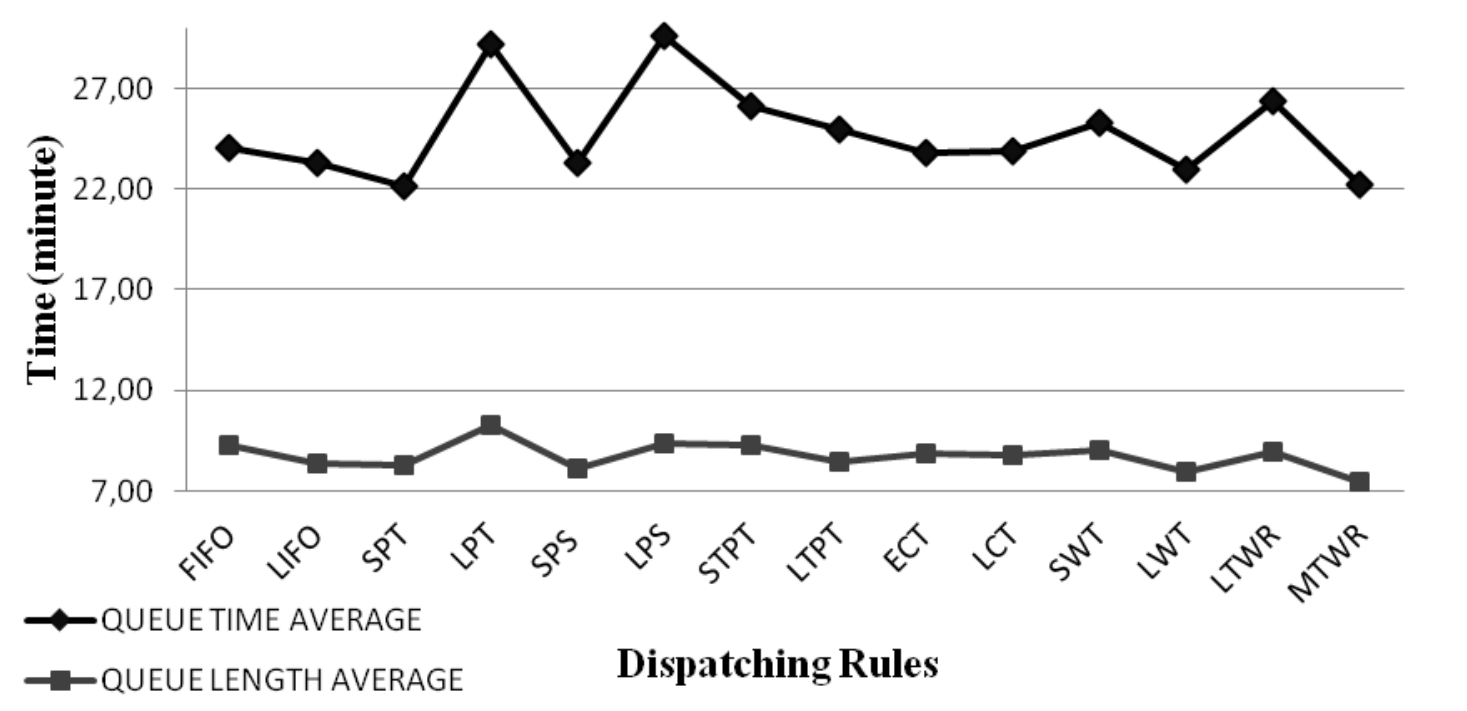

Figure 2: Performance of each single dispatching rule on queue time and queue length average.

Fig. 2 shows that SPT is the best performance in minimizing the queue time, while LPS rule creates the longest queue time in the system. MTWR rule have the best performance to 
minimize the queue length, while LPT have the worst performance for minimizing queue length.

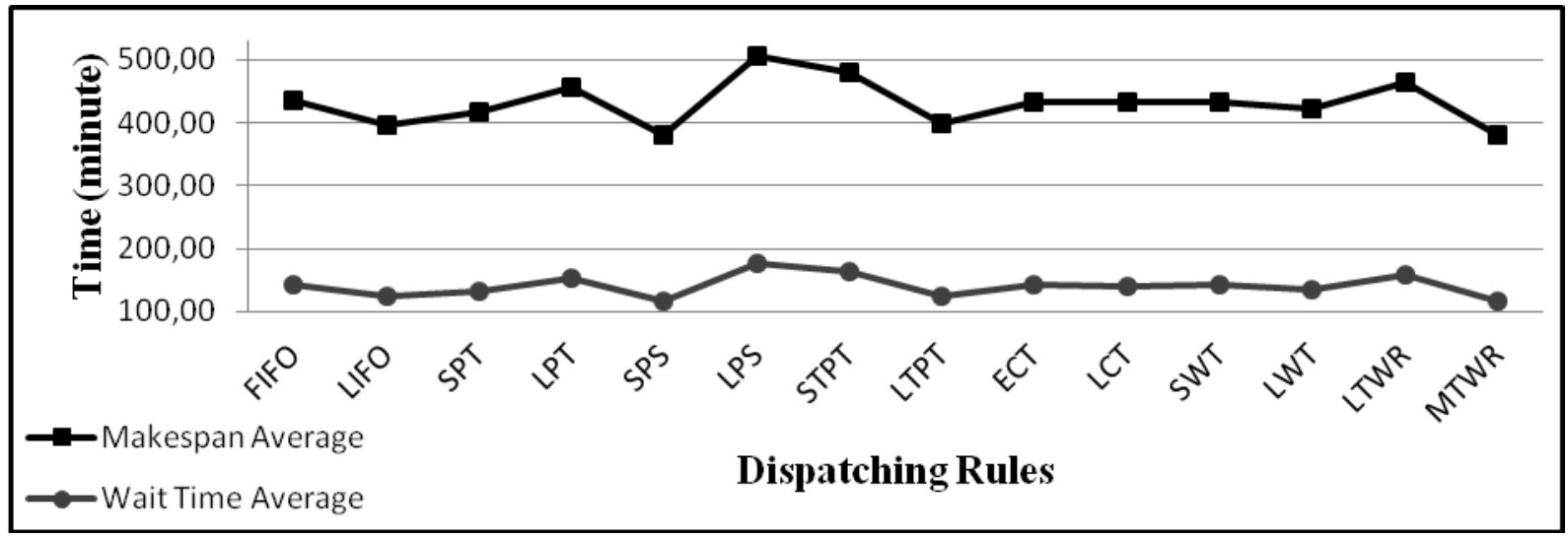

Figure 3: Performance of each single dispatching rule on waiting time and makespan.

Fig. 3 shows a similar pattern between makespan and waiting time average. It means the rule that able to minimize the average waiting time will simultaneously minimize the makespan or total time that is required to finish all the jobs in the system. MWTR rule turns out to be the best rule to minimize makespan and waiting time. In this experiment, it is unexpected to find out that the common best performers from the literature review, SPT rule, is not necessarily perform better than MWTR rule in minimizing makespan in this type of jobshop scheduling.

Analysis phase in this research conducted by comparing the experiment results based on predetermined performance measured. Each dispatching rule has a different effect on each performance measurement. There is no single dispatching rule that can achieve the objective for all measurement performance. Therefore, we give rank to each of the evaluated to determine which the best rule for each criterion. A ranking 1 will be given to the rule that gave the best performance for each criterion and 2 to the rule that gave the second best performance, and so on. The same ranking will give to the rule that has the same value. Then we summarize the ranking to find out the final ranking for all different dispatching rules. The result indicated that the rule with the minimum total rank is the best rules evaluated in this study, because it shows the consistent performance. Consistent means that the rule is able to show a constant good performance in almost all criterions.

For single dispatching rules, LWT and SPS are the best rules to enhance the WIP criterion. While for makespan criterion, MTWR and SPS were able to shows a consistent performance, meaning that these rules are performs well in almost all criterions. MTWR also able to shows a best performance in waiting time criterion, this proves that any rules that able to minimizing makespan can also minimizing waiting time. SPT the common best dispatching rule was able to improve the queue time performance in this type of job shop scheduling problem. Although SPT was able to minimize the queue time, it was not able to improve the queue length performance. LWT and MTWR show the well performance in minimizing the queue length criterion. All the single rules then compared regarding to all performance measurements to determine which best rules that performs well in almost ALL measurements. From the result obtained in Table III, we found that MTWR gives the best performance for almost ALL the measurements. It shows that the MTWR rule is able to minimize the makespan and waiting time. This rule can also create the minimum number of queue length. Meanwhile, SPT gives good results on the queue time criterion. This is a similar result with most of the existing literatures. On the other side, LPS gives the worst performance. LPT also 
shows a poor performance for most criteria's. It is similar to the existing literature that states the LPT rule have consistently poor results [24-25].

Table III: Single rules ranking.

\begin{tabular}{|c|c|c|c|c|c|c|}
\hline Rules & WIP $\boldsymbol{A} \boldsymbol{V}$ & $\boldsymbol{T T} \boldsymbol{A} \boldsymbol{V}$ & $\boldsymbol{W T} \boldsymbol{A} \boldsymbol{V}$ & $\boldsymbol{Q T} \boldsymbol{A} \boldsymbol{V}$ & $\boldsymbol{Q L} \boldsymbol{A} \boldsymbol{V}$ & Total Rank \\
\hline FIFO & 4 & 10 & 10 & 8 & 11 & 43 \\
\hline LIFO & 3 & 3 & 3 & 4 & 5 & 18 \\
\hline SPT & 5 & 4 & 5 & 1 & 4 & 19 \\
\hline LPT & 12 & 11 & 11 & 13 & 14 & 61 \\
\hline SPS & 2 & 2 & 2 & 5 & 3 & 14 \\
\hline LPS & $\mathbf{1 1}$ & $\mathbf{1 4}$ & $\mathbf{1 4}$ & $\mathbf{1 4}$ & $\mathbf{1 3}$ & $\mathbf{6 6}$ \\
\hline STPT & 7 & 13 & 13 & 11 & 11 & 55 \\
\hline LTPT & 4 & 4 & 4 & 9 & 6 & 27 \\
\hline ECT & 6 & 9 & 9 & 6 & 8 & 38 \\
\hline LCT & 9 & 7 & 7 & 7 & 7 & 37 \\
\hline SWT & 10 & 8 & 8 & 10 & 10 & 46 \\
\hline LWT & 1 & 6 & 6 & 3 & 2 & 18 \\
\hline LTWR & 8 & 12 & 12 & 12 & 9 & 53 \\
\hline MTWR & $\mathbf{4}$ & $\mathbf{1}$ & $\mathbf{1}$ & $\mathbf{2}$ & $\mathbf{1}$ & $\mathbf{9}$ \\
\hline
\end{tabular}

WIP $A V=$ Work In Progress Average

$T T A V=$ Total Time Average

$W T A V=$ Waiting Time Average

$Q T A V=$ Queue Time Average

$Q L A V$ = Queue Length Average

\subsection{Hybrid dispatching rules}

Figs. 4, 5 and 6 show the relationship between different hybrid dispatching rules to predetermined performance measurements.

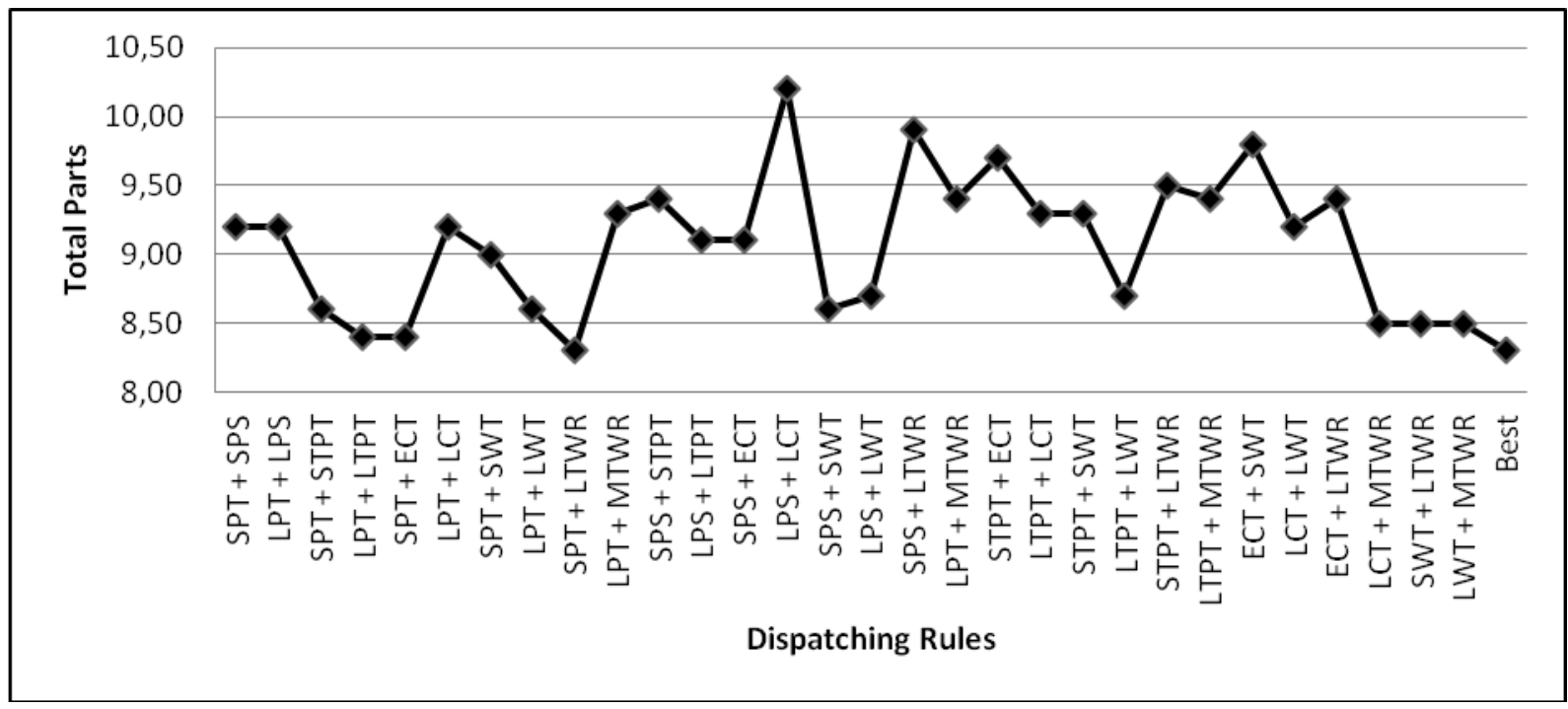

Figure 4: Performance of each hybrid dispatching rule on WIP.

Fig. 4 shows that the best rule to minimize the WIP average is combination between SPT and LTWR. For queue time performance, Fig. 5 shows that combination between SPT and ECT creates the minimum queuing time and we observed that combination between LWT and MTWR is able to create the minimum queue length of job in the system. It was noted from 
Fig. 6 that the combination between SPS and ECT is capable in minimizing both waiting time and makespan.

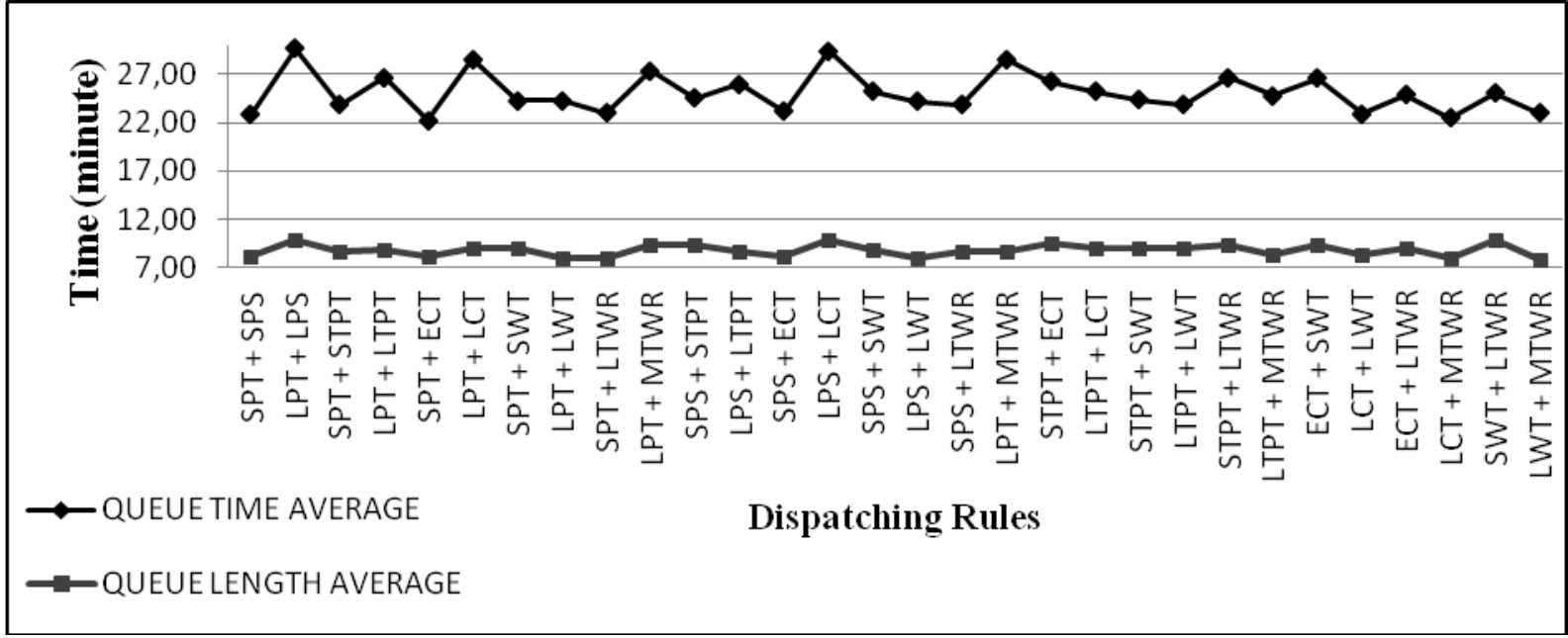

Figure 5: Performance of each hybrid dispatching rule on queue time and queue length average.

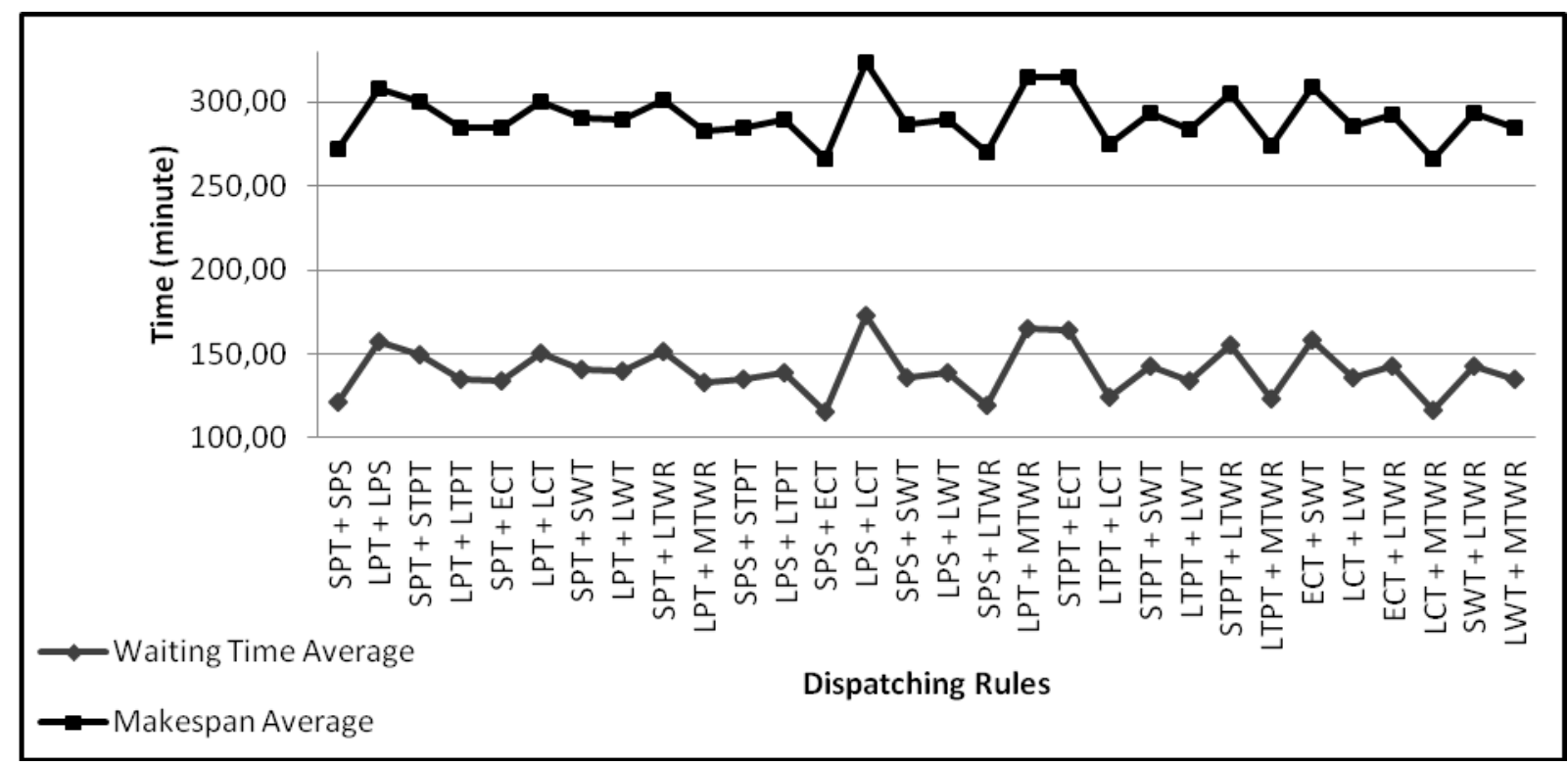

Figure 6: Performance of hybrid dispatching rule on waiting time and makespan average.

For hybrid dispatching rules, the combination between SPT and LTWR was able to perform well in WIP criterions. For makespan and waiting time criterion, the combination between SPS and ECT shows the best performance. It is similar with the finding in single rule, the rule that able to minimize the makespan is also able to minimize the waiting time. Hybrid rule SPT and ECT shows the best performance in queue time criterion and the combination rule between LWT and MTWR shows the best performance for queue length average. All the hybrid rules then compared regarding to all performance measurements to determine which best rules that performs well in almost ALL measurements. From Table IV, the combination between LCT and MTWR gives the best performance for almost ALL the measurements. The combination between SPS and ECT also shows a good performance, followed by SPT and SPS. Meanwhile, the combination of LPS and LCT gives the worst performance for most measurements. It shows the worst ranking at almost all criteria. 
Table IV: Hybrid rules ranking.

\begin{tabular}{|c|c|c|c|c|c|c|}
\hline Rules & WIP AV & $\boldsymbol{T T} \boldsymbol{A} \boldsymbol{V}$ & $\boldsymbol{W T} \boldsymbol{A} \boldsymbol{Q}$ & $\boldsymbol{Q T} \boldsymbol{A} \boldsymbol{Q}$ & $\boldsymbol{Q} \boldsymbol{A} \boldsymbol{V}$ & Total Rank \\
\hline SPT+SPS & 8 & 4 & 4 & 3 & 6 & 25 \\
\hline LPT+LPS & 8 & 26 & 26 & 30 & 28 & 118 \\
\hline SPT+STPT & 4 & 22 & 22 & 10 & 13 & 71 \\
\hline LPT+LTPT & 2 & 12 & 12 & 24 & 16 & 66 \\
\hline SPT+ECT & 2 & 9 & 9 & 1 & 6 & 27 \\
\hline LPT+LCT & 8 & 23 & 23 & 28 & 19 & 101 \\
\hline SPT+SWT & 6 & 18 & 18 & 13 & 17 & 72 \\
\hline LPT+LWT & 4 & 17 & 17 & 12 & 2 & 52 \\
\hline SPT+LTWR & 1 & 24 & 24 & 5 & 3 & 57 \\
\hline LPT+MTWR & 9 & 7 & 7 & 26 & 24 & 73 \\
\hline SPS+STPT & 11 & 10 & 11 & 15 & 24 & 71 \\
\hline LPS+LTPT & 7 & 16 & 16 & 21 & 11 & 71 \\
\hline SPS+ECT & 7 & 1 & 1 & 7 & 6 & 22 \\
\hline LPS+LCT & $\mathbf{1 5}$ & $\mathbf{3 0}$ & $\mathbf{3 0}$ & $\mathbf{2 9}$ & $\mathbf{3 0}$ & $\mathbf{1 3 4}$ \\
\hline SPS+SWT & 4 & 14 & 14 & 19 & 15 & 66 \\
\hline LPS+LWT & 5 & 15 & 15 & 11 & 3 & 49 \\
\hline SPS+LTWR & 14 & 3 & 3 & 9 & 13 & 42 \\
\hline LPS+MTWR & 11 & 29 & 29 & 27 & 11 & 107 \\
\hline STPT+ECT & 27 & 28 & 29 & 22 & 27 & 133 \\
\hline LTPT+LCT & 9 & 6 & 6 & 20 & 19 & 60 \\
\hline STPT+SWT & 9 & 20 & 20 & 14 & 17 & 80 \\
\hline LTPT+LWT & 5 & 8 & 8 & 8 & 19 & 48 \\
\hline STPT+LTWR & 12 & 25 & 25 & 25 & 23 & 110 \\
\hline LTPT+MTWR & 11 & 5 & 5 & 16 & 9 & 46 \\
\hline ECT+SWT & 13 & 27 & 27 & 23 & 24 & 114 \\
\hline LCT+LWT & 8 & 13 & 13 & 4 & 10 & 48 \\
\hline ECT+LTWR & 10 & 19 & 19 & 17 & 22 & 87 \\
\hline LCT+MTWR & $\mathbf{3}$ & $\mathbf{2}$ & $\mathbf{2}$ & $\mathbf{2}$ & $\mathbf{3}$ & $\mathbf{1 2}$ \\
\hline SWT+LTWR & 3 & 21 & 21 & 18 & 28 & 91 \\
\hline LWT+MTWR & 3 & 11 & 10 & 6 & 1 & 31 \\
\hline
\end{tabular}

\subsection{Comparison of single and hybrid dispatching rules}

From the results obtained, we compare the best single and hybrid rules and determine which the best rules among all the selected rules in this project. Table V shows the comparison between these rules.

For this type of factory with job shop scheduling problem, the single rule MTWR become the best rule amongst other single dispatching rules evaluated in this experiment. It improves most of the factory performance measurements especially the average makespan, average waiting time and average queue length. It is also unexpected to find that by combining scheduling parameters in dispatching rules with multiplicative method, it do not necessarily enhance performance of the factory.

\section{CONCLUSION}

Arena simulation software used to constructs a job-shop simulation model based on the real data. This study evaluates the impact of various single and hybrid dispatching rules by using simulation technology regarding to its performance measurements such as WIP, makespan, waiting time, queue time, and queue length. 
Table V: Comparison hybrid and single dispatching rules.

\begin{tabular}{|c|c|c|c|c|c|}
\hline \multicolumn{2}{|c|}{ Performance } & Single & Hybrid & \multicolumn{2}{|c|}{ Rank } \\
\hline \multirow{2}{*}{ Order } & Total & 5401.8 & 5396 & 1 & 2 \\
\cline { 2 - 6 } & Output & 5379.8 & 5373.8 & 1 & 2 \\
\hline \multirow{3}{*}{ WIP } & Average & 8.7 & 8.5 & 2 & 1 \\
\cline { 2 - 6 } & Min & 15 & 14 & 2 & 1 \\
\cline { 2 - 6 } & Max & 4 & 4 & 1 & 1 \\
\hline \multirow{3}{*}{$\begin{array}{c}\text { Total } \\
\text { Time }\end{array}$} & Average & 265.55 & 266.42 & 1 & 2 \\
\cline { 2 - 6 } & Min & 422.41 & 420.33 & 2 & 1 \\
\cline { 2 - 6 } & Max & 152.43 & 158.97 & 1 & 2 \\
\hline \multirow{3}{*}{$\begin{array}{c}\text { Waiting } \\
\text { Time }\end{array}$} & Average & 115.09 & 115.97 & 1 & 2 \\
\cline { 2 - 6 } & Min & 162.3 & 161.46 & 2 & 1 \\
\cline { 2 - 6 } Queue & Max & 54.46 & 61.05 & 1 & 2 \\
\cline { 2 - 6 } Time & Average & 22.25 & 22.53 & 1 & 2 \\
\hline \multirow{2}{*}{$\begin{array}{c}\text { Queue } \\
\text { Length }\end{array}$} & Average & 7.4615 & 8 & 1 & 2 \\
\cline { 2 - 6 } & Max & 20 & 21 & 1 & 2 \\
\cline { 2 - 6 } & Min & 1 & 2 & 1 & 2 \\
\hline \multirow{2}{*}{} & & Total & 20 & 27 \\
\hline
\end{tabular}

The total of 44 rules that consists 14 single rules and 30 hybrid rules are compared to determine which rule that performs well for all measured performance. After the analysis, the result has shown no single rule that effectively improve all the performances. In that case, we summarize the rank of dispatching rules. The combination between MTWR and LCT found to be the best combination and MTWR rule turns out to be the best single rule among all the rules tested in this project. The result also indicated that the hybrid dispatching rules do not generate the best rules compared to the single dispatching rule. The result of the case study reported in this project is expected to provide the company with useful information for the manager to choose appropriate sequencing rules that proven able to improve the plant performance regarding its performance measured.

It is unexpected to find out that the common best performance, SPT rule is not perform better than the MTWR rule for the data tested. The results also indicate that future research could be directed towards the development of rules by combination of more than two rules so that the performance measures can be further optimized and identify the impact of dispatching rules based on resources utilization instead of time. The investigation of other similar or more complex ways of combining the efficiency of different dispatch rules, on the basis of equations and with the use of other search or optimization approaches, or by adding more scheduling parameters into the sequencing rules such as due date, routing flexibility, are some of the ideas that could be further explored. Suggestions for further research also include investigating any scheduling algorithm in improving the job-shop scheduling problem by using the simulation method.

\section{REFERENCES}

[1] Terzia, S.; Cavalierib, S. (2004). Simulation in the supply chain context: a survey, Computers in Industry, Vol. 53, No. 1, 3-16, doi:10.1016/S0166-3615(03)00104-0

[2] Vinod, V.; Sridharan, R. (2008). Dynamic job-shop scheduling with sequence-dependent setup times: simulation modeling and analysis, Int. Journal of Advanced Manufacturing Technology, Vol. 36, No. 3-4, 355-372, doi:10.1007/s00170-006-0836-4

[3] Yan, Y.; Wang, G. (2007). A Job Shop Scheduling Approach Based on Simulation Optimization, Proceedings of the 2007 IEEE, 1816-1822 
[4] Boris, J.; Patnaik, G.; Lee, M. Y.; Young, T.; Leitl, B.; Harms, F.; Schatzmann, M. (2009).Validation of an LES Urban Aerodynamics Model for Homeland Security, Proceedings of $47^{\text {th }}$ AIAA Aerospace Sciences Meeting, 5-8

[5] Song, J.; Lei, W.; Bei, N.; Zavala, M.; de Foy, B.; Volkamer, R.; Cardenas, B.; Zheng, J.; Zhang, R.; Molina, L. T. (2010). Ozone response to emission changes: a modeling study during the 30 MCMA-2006/MILAGRO Campaign, Atmospheric Chemistry and Physics, Vol. 10, 3827-3846, doi:10.5194/acp-10-3827-2010

[6] Gupta, A. K.; Sivakumar, A. I. (2006). Job shop scheduling techniques in semiconductor manufacturing, Int. Journal of Advanced Manufacturing Technology, Vol. 27, No. 11-12, 11631169, doi:10.1007/s00170-004-2296-z

[7] Kapanoglu, M.; Alikalfa, M. (2011). Learning IF-THEN priority rules for dynamic job shops using genetic algorithms, Robotics and Computer-Integrated Manufacturing, Vol. 27, No. 1, 4755, doi:10.1016/j.rcim.2010.06.001

[8] Pinedo, M. (1995). Scheduling: Theory, Algorithms, and Systems, Prentice Hall, Englewood Cliffs

[9] Rajabinasab, A.; Mansour, S. (2011). Dynamic flexible job shop scheduling with alternative process plans: an agent-based approach, Int. Journal of Advanced Manufacturing Technology, Vol. 54, No. 9-12, 1091-1107, doi:10.1007/s00170-010-2986-7

[10] Panwalkar, S. S.; Iskander, W. (1977).A Survey of Scheduling Rules, Operations Research, Vol. 25, No. 1, 45-61, doi:10.1287/opre.25.1.45

[11] Holthaus, O.; Rajendran, C. (1997). Efficient dispatching rules for scheduling in a job shop, Int. Journal of Production Economics, Vol. 48, No. 1, 87-105, doi:10.1016/S0925-5273(96)00068-0

[12] Papakostas, N.; Chryssolouris, G. (2009). A Scheduling Policy for Improving Tardiness Performance, AIJSTPME, Vol. 2, No. 3, 79-89

[13] Kim, I.; Watada, J.; Shigaki, I. (2008). A comparison of dispatching rules and genetic algorithms for job shop schedules of standard hydraulic cylinders, Soft Computing, Vol. 12, No. 1, 121-128

[14] Barman, S.; Lisboa, J. V. (2010). Cost performance of simple priority rule combinations, Journal of Manufacturing Technology Management, Vol. 21, No. 5, 567-584, doi:10.1108/ 17410381011046977

[15] Ko, H. H.; Kim, J.; Kim, S. S.; Baek, J. G. (2010). Dispatching rule for non-identical parallel machines with sequence-dependent setups and quality restrictions, Computers \& Industrial Engineering, Vol. 59, No. 3, 448-457, doi:10.1016/j.cie.2010.05.017

[16] Slak, A.; Tavcar, J.; Duhovnik, J. (2011). Application of genetic algorithm into multicriteria batch manufacturing scheduling, Strojniski vestnik - Journal of Mechanical Engineering, Vol. 57, No. 2, 110-124, doi:10.5545/sv-jme.2010.122

[17] Abrashi, A.; Stefanic, N.; Lisjak, D. (2010). Solving JSSP by introducing Hamilton similarity and time dependent fitness scaling, Strojniski vestnik - Journal of Mechanical Engineering, Vol. 56, No. 5, 330-339

[18] Greenwood, F. (1989). Introduction to Computer-Integrated Manufacturing, Harcourt Brace Jovanovich, San Diego

[19] Toomey, J. W. (1996). MRP II: Planning for Manufacturing Excellence, Chapman \& Hall, NY

[20] Othman, Z. (2002). Pendekatan berintegrasi dalam penjadualan pengeluaran menggunakan kaedah algoritma genetic, $\mathrm{PhD}$ Thesis, Universiti Sains Malaysia

[21] Dileepan, P.; Ahmadi, M. (2010). Scheduling rules for a small dynamic job-shop: a simulation approach, Int. Journal of Simulation Modelling, Vol. 9, No. 4, 173-183, doi:10.2507/ IJSIMM09(4)1.165

[22] Chan, F. T. S. (2001). The effects of routing flexibility on a flexible manufacturing system, Computer Integrated Manufacturing, Vol. 14, No. 5, 431-435, doi:10.1080/09591120010021793

[23] Rockwell Software (2009). ARENA Standard Training Course

[24] Sarper, H; Henry, M. C. (1996). Combinatorial Evaluation of Six Dispatching Rules in a Dynamic Two-machine Flow Shop, Omega, Vol. 24, No. 1, 73-81, doi:10.1016/03050483(95)00049-6

[25] Barrett, R. T; Barman, S. (1986). A SLAM II simulation study of a simplified flow shop, Simulation, Vol. 47, No. 5, 181-189, doi:10.1177/003754978604700502 